\title{
Investigating various application areas of three-dimensional virtual worlds for higher education
}

\section{Reza Ghanbarzadeh and Amir Hossein Ghapanchi}

Reza Ghanbarzadeh is a PhD candidate at the School of Information and Communication Technology, Griffith University, Queensland, Australia. His research interests mainly focus on Information Systems and particularly on adoption of innovations in different fields of study. Dr Amir Hossein Ghapanchi is a senior lecturer at the School of Information and Communication Technology, Griffith University, Queensland, Australia. His research interests include organisational and individuals' uptake of technology, health informatics and electronic learning. Address for correspondence: Reza Ghanbarzadeh, Department of Information and Communication Technology, Griffith University, 4222, Queensland, Australia.Email: Reza.ghanbarzadeh@griffithuni.edu.au

\begin{abstract}
Three-Dimensional Virtual World (3DVW) have been adopted extensively in the education sector worldwide, and there has been remarkable growth in the application of these environments for distance learning. A wide variety of universities and educational organizations across the world have utilized this technology for their regular learning and teaching programs. The current study conducts a systematic review of the published studies relevant to the application of 3DVWs in higher education. A search of the literature was carried out in eight high-ranking scientific digital libraries. Following scrutiny according to inclusion and exclusion criteria, 165 papers out of 1,402 publications were selected for review from a variety of disciplines over a 10-year time period. The systematic review process were summarized, a number of paper reviews were conducted and results in conjunction with applicability of 3DVWs in higher education were extracted. In this study, various application areas of 3DVWs in higher education were found and classified into 13 main categories. Additionally, implications for research and practice are presented to provide new directions for further research and practice in the field.
\end{abstract}

Keywords: Three-dimensional virtual worlds; education; e-learning; distance learning; higher education

\section{Practitioner's Notes}

What is already known about this topic:

- Rapid advances in information and communication technology are transforming the teaching and learning styles, and education is incorporating more and more of the capabilities provided by the Internet.

- Three-Dimensional Virtual Worlds (3DVW) technology, as an innovative approach, is applied in pedagogical and educational systems.

- During the last decade, educators from a wide variety of backgrounds have started to use this cutting-edge technology in their teaching and learning programs.

\section{What this paper adds:}

- Conducts a systematic literature review on the published studies relevant to the application of 3DVW technology in the higher education sector. 
- Provides insights into pedagogical applications of 3DVWs that have the potential to reshape the teaching and learning practice.

- Provides a comprehensive taxonomy of application areas of 3DVWs in higher education including various meaningful categories and sub-categories for the educational community.

- Offers educators and educational institutions some implications and informed directions in conjunction with utilizing 3DVWs to achieve specific teaching and learning outcomes, and highlights areas where some adaptation of the 3DVWs for higher education programs is needed.

\section{Implications for practice and/or policy:}

- The education community can use this technology as a creative, powerful and efficient tool to develop novel and effective styles of teaching and learning by performing various pedagogical activities.

- These environments provide great facilities for creating, mixing, and mashing up objects and content, as well as performing educational activities such as virtual classrooms, virtual labs, simulations, machinima, socialization, virtual field trips and so on.

- Further studies need to investigate the issues and barriers of using 3DVWs in the higher education sector.

- There is a need for further research applying quantitative, qualitative and mixed method approaches in this field to achieve results that can be better generalized and better examine students' and educators' perceptions of how 3DVWs undergo changes.

\section{Introduction}

One of the promising and admirable innovations in the field of Information and Communication Technologies (ICT) is the Three-Dimensional Virtual World (3DVW) platform (Firat, 2010). A 3DVW is a three-dimensional, Internet-based, networked, multimedia, simulated and graphical environment that runs on the Internet and is intended for users to inhabit and interact with using their own animated, graphical and digital selfrepresentations known as avatars (Boulos, Hetherington, \& Wheeler, 2007). These virtual worlds can be considered online locations where individuals can interact with 3D embodiments of physical locations or phenomena. In most 3DVWs, the principle rules of physics for environments continue to hold, which makes navigation inside them resemble what one is used to in the real world. They have the ability to share a specific virtual environment, enabling users to perform tasks with a high synchronous level of collaboration to manipulate similar virtual objects. Recently, 3DVWs have thrived tremendously and affect the way people communicate and interact with each other (Ba, Ke, Stallaert, \& Zhang, 2010). In these environments, there is a possibility for not only simulating real-world actions as they are but for creating new and different dreamy worlds as well (De Lucia, Francese, Passero, \& Tortora, 2009).

Over the past decade, the number of 3DVW users has risen drastically (Gorini, Gaggioli, Vigna, \& Riva, 2008). According to KZero (2013), there are more than 200 commercially available virtual world platforms with about 40 million registered accounts, although these could represent multiple accounts of individual users. The growing trend in the number of users visiting or using 3DVWs is an indicator of the depth of applicability and attractiveness of this technology. For example, Second Life (www.secondlife.com), developed by Linden Lab in 2003, is one of the largest and most popular 3DVWs. The population of Second Life exceeded 36 million in 2013 and has grown by more than 6 times since 2007 (Linden Lab, 2013).

Educational systems increasingly incorporate the capabilities provided by the Internet, and prompt developments in ICT are reforming teaching and learning methods. One of the 
obvious samples of application of ICT-based technologies is the incorporation of 3DVWs in teaching and learning (Blair \& Lin, 2011). These virtual words have a significant potential for the development of the next generation of educational environments. Educational systems across the world increasingly are using them as an advanced platform for distance education and e-learning. These immersive platforms provide the capabilities for creating sophisticated and highly interactive learning environments that use simulating, programming, modelling and application of scripting tools. They present opportunities to become an optimal educational platform by providing collaborative teaching and learning spaces. A variety of universities, schools and other pedagogical communities across the world are paying more attention to the teaching and learning aids which can be provided within 3DVWs.

Several studies have been conducted to observe the effects of using 3DVWs in education settings. Duncan, Miller, and Jiang (2012) synthesized more than 100 published academic papers, reports and educational websites, focusing on the applications of virtual worlds in education. Merchant, Goetz, Cifuentes, Keeney-Kennicutt, and Davis (2014) performed a meta-analysis to examine the overall effect and impact of instructional design principles in kindergarten through grade $12(\mathrm{~K}-12)$ or higher education settings based on virtual reality technologies. Although there are various studies explaining the fact that 3DVWs can provide a unique and flexible environment for teaching and learning without the restrictions of distance and space, a detailed big picture of feasible educational activities based on this technology in higher education is less well understood by the educational systems and researchers interested in this area. The significance of this cutting-edge technology in the education sector, the considerable attention from academic sector and the lack of a comprehensive taxonomy of application areas of this technology in the higher education sector encouraged the authors to conduct a review of the literature to create an extensive picture of 3DVWs and their utilization areas in higher education.

The primary objective of this article is to provide a comprehensive, systematic review of the literature reporting on various application areas of 3DVWs in higher education. The secondary objective is to identify any neglected or under-researched aspects of 3DVWS in the education sector. Thus, this study attempts to respond to the following research question: For what purposes have 3DVW technologies been applied in the higher education sector? In other words, what are the various application areas of 3DVWs for higher education?

\section{Method}

\section{Summary}

The wider context of this study is to investigate several application areas of 3DVWs in higher education. To explore the efforts made in this area, this study was conducted as a systematic review of the body of knowledge according to guidelines proposed by Kitchenham (2004). A systematic literature review is a methodical approach for identifying, evaluating and interpreting previous studies conducted in a specific research field (Kitchenham, 2004).

The stages in research methodology are described, and the processes of paper inclusion and exclusion as well as extracting and analysing data are identified.

\section{Search and Selection}

The process of searching for appropriate literature was performed in six stages. Figure 1 depicts the stages of selecting papers for the review. 


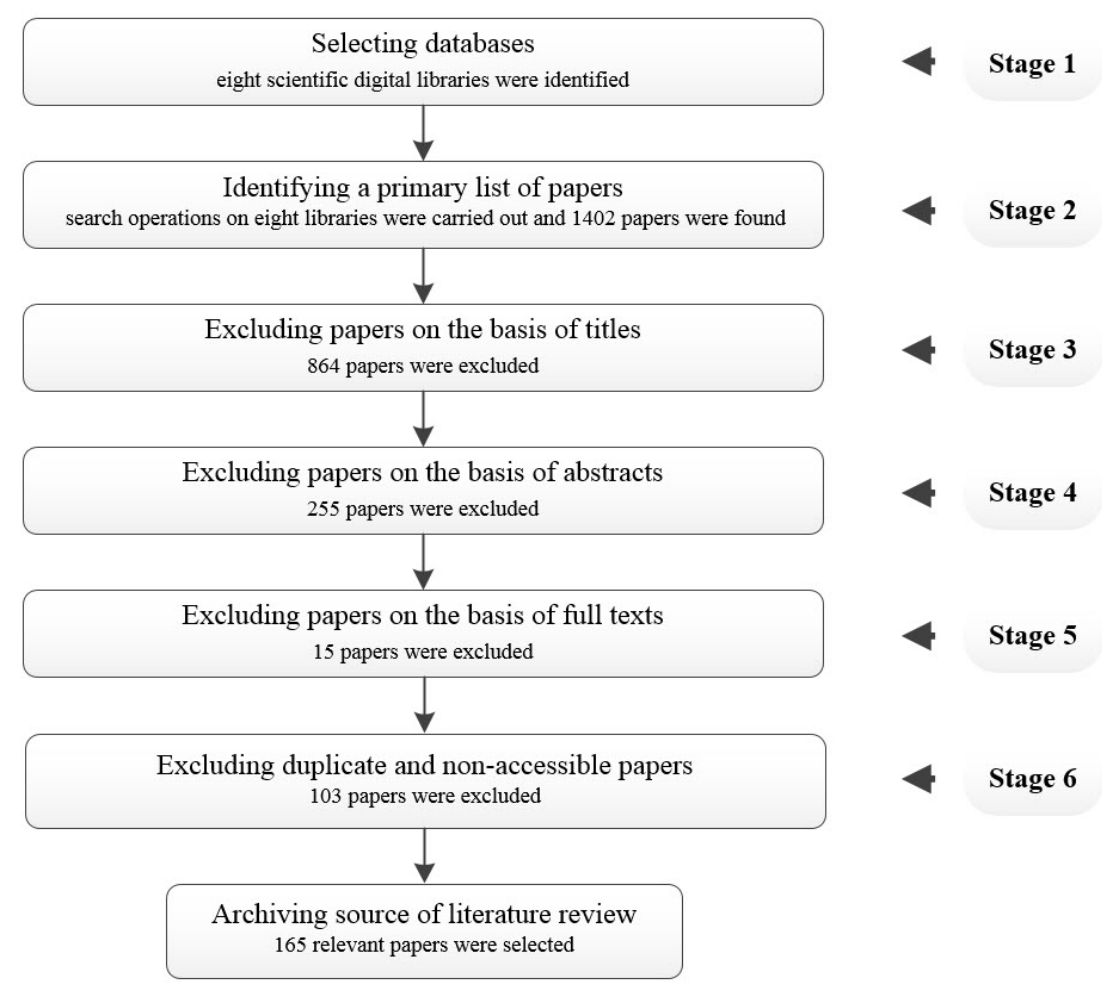

Figure 1. Stages in the procedure of selecting papers.

In the first stage, eight main scientific digital libraries for the search of keywords were identified: ScienceDirect, ProQuest Computing, IEEE Xplore, AISeL, Inspec, Web of Science, ERIC, and PsycARTICLES. We believe that the choice of these eight libraries was reasonable because together they cover thousands of peer-reviewed journals and conferences.

In Stage 2, we used a set of keywords and search terms to carry out search operations in the digital libraries. The advanced search services provided by each of the digital libraries were used to search a combination of title, abstract and keywords of the papers by applying 48 search terms demonstrated in Figure 2. A filtration based on publication date was performed in the search process. As of 15 November, 2013, our search operations revealed 1,402 primary papers. 'Appendix A' shows a list of queries used in the search process in each digital library.

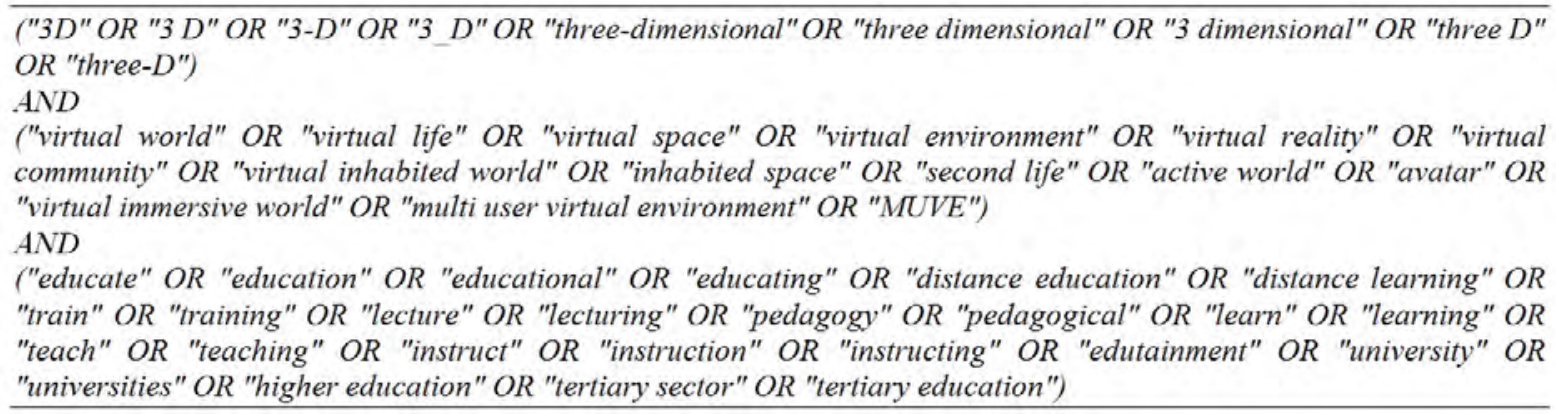

Figure 2. Search term statements.

In Stage 3, we reviewed all of the papers' titles one by one and excluded 864 papers with completely irrelevant topics, according to their title. In Stage 4, we refined the collection of papers by reading the abstracts of the remaining 538 papers and eliminating 255 irrelevant 
papers. In Stage 5, we read full text of the remaining papers and excluded 15 based on irrelevant full text. In Stage 6, we found 67 duplicate papers among the eight libraries. Additionally, there was no electronic access to the full text of 36 papers. At the end of the search and selection procedure, the total number of selected papers was 165 . Table 1 presents a summary of the search and selection process, in accordance with each scientific digital library.

Table 1. Summary of search process and selecting papers divided by digital libraries

\begin{tabular}{|c|c|c|c|c|c|c|c|}
\hline Digital Library & $\begin{array}{c}\text { Total Number } \\
\text { of Papers }\end{array}$ & $\begin{array}{l}\text { Excluded } \\
\text { by Title }\end{array}$ & $\begin{array}{c}\text { Excluded } \\
\text { by Abstract }\end{array}$ & $\begin{array}{c}\text { Excluded } \\
\text { by Full Text }\end{array}$ & Duplicate & $\begin{array}{c}\text { No Full } \\
\text { Text }\end{array}$ & $\begin{array}{c}\text { Related } \\
\text { Papers }\end{array}$ \\
\hline ScienceDirect & 249 & 148 & 73 & 1 & 0 & 0 & 27 \\
\hline PsycARTICLES) & 20 & 13 & 6 & 1 & 0 & 0 & 0 \\
\hline IEEE Xplore & 573 & 433 & 63 & 6 & 9 & 0 & 62 \\
\hline ERIC & 194 & 56 & 47 & 4 & 30 & 19 & 38 \\
\hline Inspec & 53 & 8 & 17 & 1 & 2 & 6 & 19 \\
\hline Web of Science & 66 & 15 & 21 & 0 & 21 & 7 & 2 \\
\hline AISeL & 23 & 1 & 6 & 2 & 0 & 2 & 12 \\
\hline ProQuest Computing & 224 & 190 & 22 & 0 & 5 & 2 & 5 \\
\hline Total & 1,402 & 864 & 255 & 15 & 67 & 36 & 165 \\
\hline
\end{tabular}

\section{Data Extraction}

During the data extraction phase, three types of data were extracted from the selected studies:

i. 3DVWs and their applications in higher education

ii. Participant population of 3DVWs in educational activities

iii. Demographic data such as country of publication and year of publication

\section{Data Analysis}

We performed data analysis on the selected studies by first reading the full text of all 165 papers and, based on the main area of the study of each paper, extracting the area of application of the technology with regard to a higher education context. To perform the data analysis, three separate reviews were carried out by three different researchers.

In the first review, the first researcher read each paper and assigned a suitable label with an appropriate application category name, indicating the area of the application of the technology. Papers with a similar label were classified into one category until, at the end, all papers were classified into different categories. Finally, the papers in each category were divided into sub-categories and sub-sub-categories based on their similarities.

The second and third researchers performed a similar review process independently, producing second and third classifications. The results of the three reviews were discussed in a group meeting including the authors and other professionals in the field of information systems. During the meeting, all labels, categories, sub-categories and sub-sub-categories of the three different reviews were revised. Finally, activities in all of the 165 papers were grouped into 13 major categories with sub-categories and sub-sub-categories, and a comprehensive taxonomy of application areas of the technology in higher education was provided.

Afterward, additional data such as the participant population in activities, year and country of publication were extracted from the articles. Figure 3 shows the process of data analysis in the current study. 


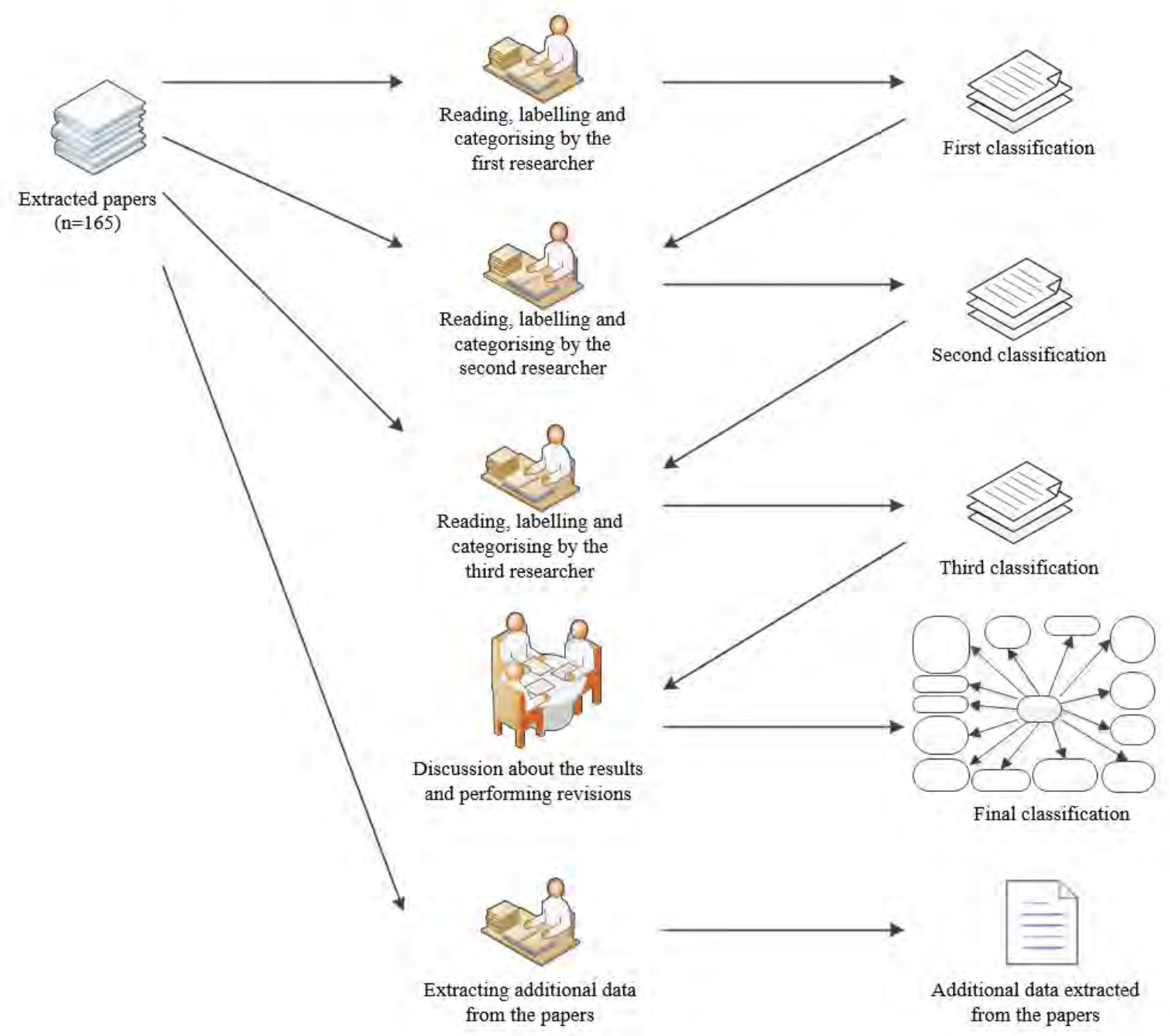

Figure 3. Stages in the procedure of data analysis.

\section{Results}

The study results are presented in three parts. The first part presents demographic information identifying frequency of publications in the literature per year as well as distribution of papers from various countries. The second section provides a comprehensive overview of application areas of 3DVWs in higher education with a taxonomy and a description of each category. The third section provides information about the participant population of 3DVWs in higher education.

\section{Demographic Information}

Figure 4 illustrates the frequency of published studies per year from 2003 to 2013. There was no papers related to this topic between 1990 and 2002. The search was extended to such a great length of time because the earliest examples of 3DVWs appeared from the 1970s. Maze War (1974), Habitat (1986), and Worlds Chat (1995) are some examples of the early generations of virtual worlds (Damer, 2008). The search results, however, demonstrate that this technology was considered by researchers only after 2003. As can be seen from Figure 4, there were only seven papers between 2003 and 2006, and the number of papers jumped from eight to 38 between 2007 and 2010. There was a decrease to 24 in 2011, 
increasing to 31 in 2012. The search took place in November 2013, and 14 papers were published in 2013 prior to November.

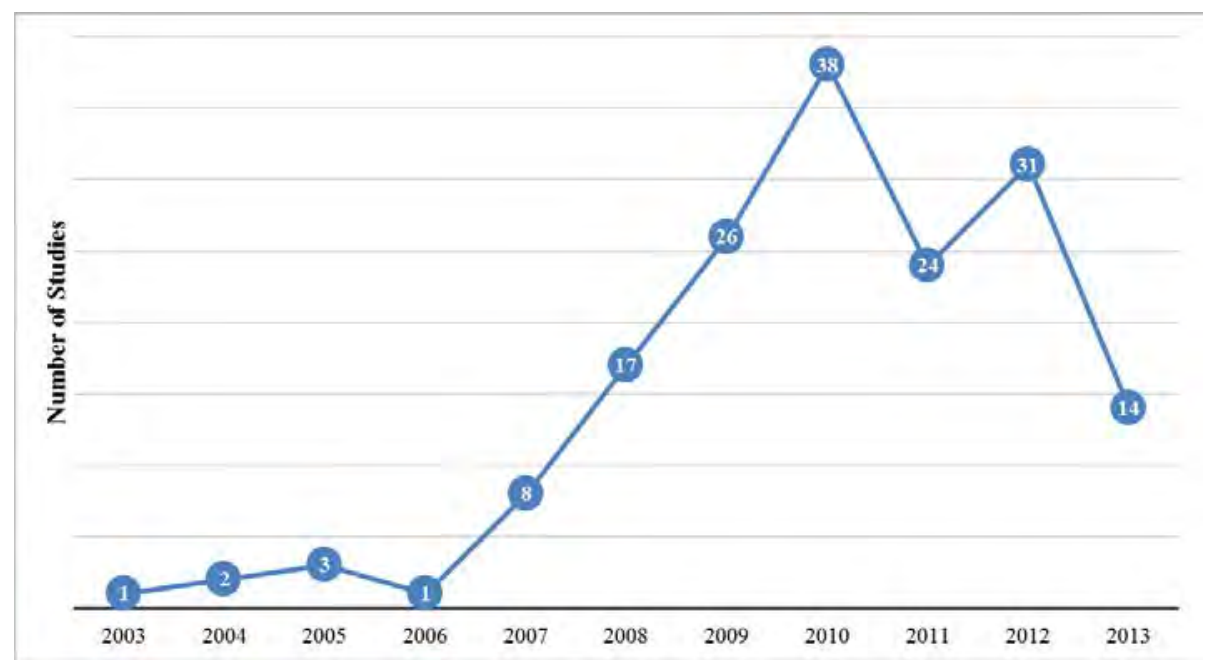

Figure 4. Distribution of papers per year.

Figure 5 represents the percentage of published papers from the study according to the different countries across the world. Almost $22 \%$ of the papers were from the United States. The next major source of papers was the United Kingdom with 18\%; followed by China with 9\%; Australia with 7\%; and Japan, Taiwan and Greece with 5\% each. The remaining 29\% of publications came from countries such as Singapore, Brazil, Germany, Norway, Spain, Turkey, and others. Table 2 shows the number of published papers by country.

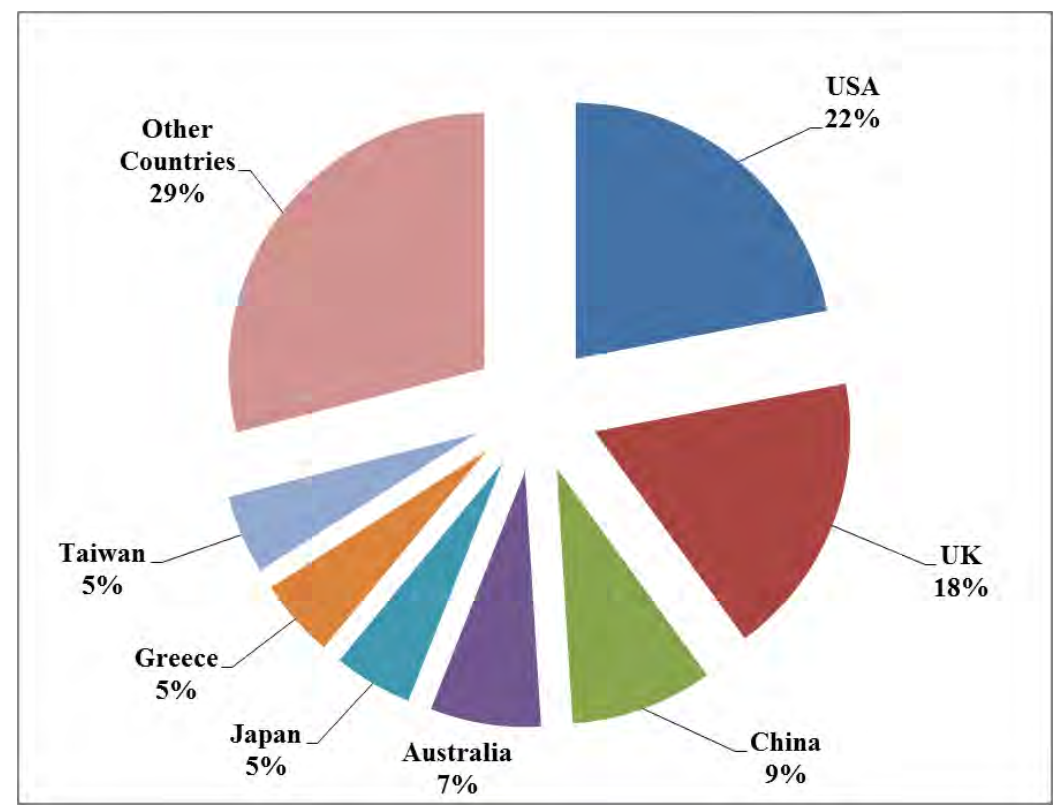

Figure 5. Distribution of papers from various countries.

Table 2. Number of papers published from various countries across the world

\begin{tabular}{|c|c|c|c|}
\hline Country & $\begin{array}{c}\text { Number of } \\
\text { published papers }\end{array}$ & Country & $\begin{array}{c}\text { Number of } \\
\text { published papers }\end{array}$ \\
\hline USA & 36 & Hong Kong & 3 \\
\hline UK & 29 & Italy & 3 \\
\hline China & 15 & Portugal & 3 \\
\hline Australia & 11 & Russia & 3 \\
\hline Japan & 9 & Austria & 2 \\
\hline
\end{tabular}




\begin{tabular}{|c|c|c|c|}
\hline Greece & 8 & The Netherlands & 2 \\
\hline Taiwan & 8 & Canada & 1 \\
\hline Singapore & 5 & France & 1 \\
\hline Spain & 5 & Scotland & 1 \\
\hline Germany & 4 & New Zealand & 1 \\
\hline Norway & 4 & Northern Ireland & 1 \\
\hline Brazil & 4 & South Korea & 1 \\
\hline Turkey & 4 & India & 1 \\
\hline
\end{tabular}

\section{Taxonomy of Application Areas of 3DVWs in Higher Education}

After a thorough literature search and analysis, various application areas of 3DVWs in higher education were compiled from the literature and distilled into 13 categories based on supporting evidence: virtual lecturing, virtual laboratory, field trip, simulation, meeting and discussion, assessment, gaming and machinima, course material, curricular services, socialization, in-world creation, student activities and miscellaneous activities. All categories are associated with sub-categories and sub-sub-categories. Figure 6 depicts the taxonomy of application areas. Some of the papers contained more than one activity in their study; therefore, they were included in different categories. 'Appendix B' shows a bibliography of the analysed papers in each category. All of the categories are explained in the current section.

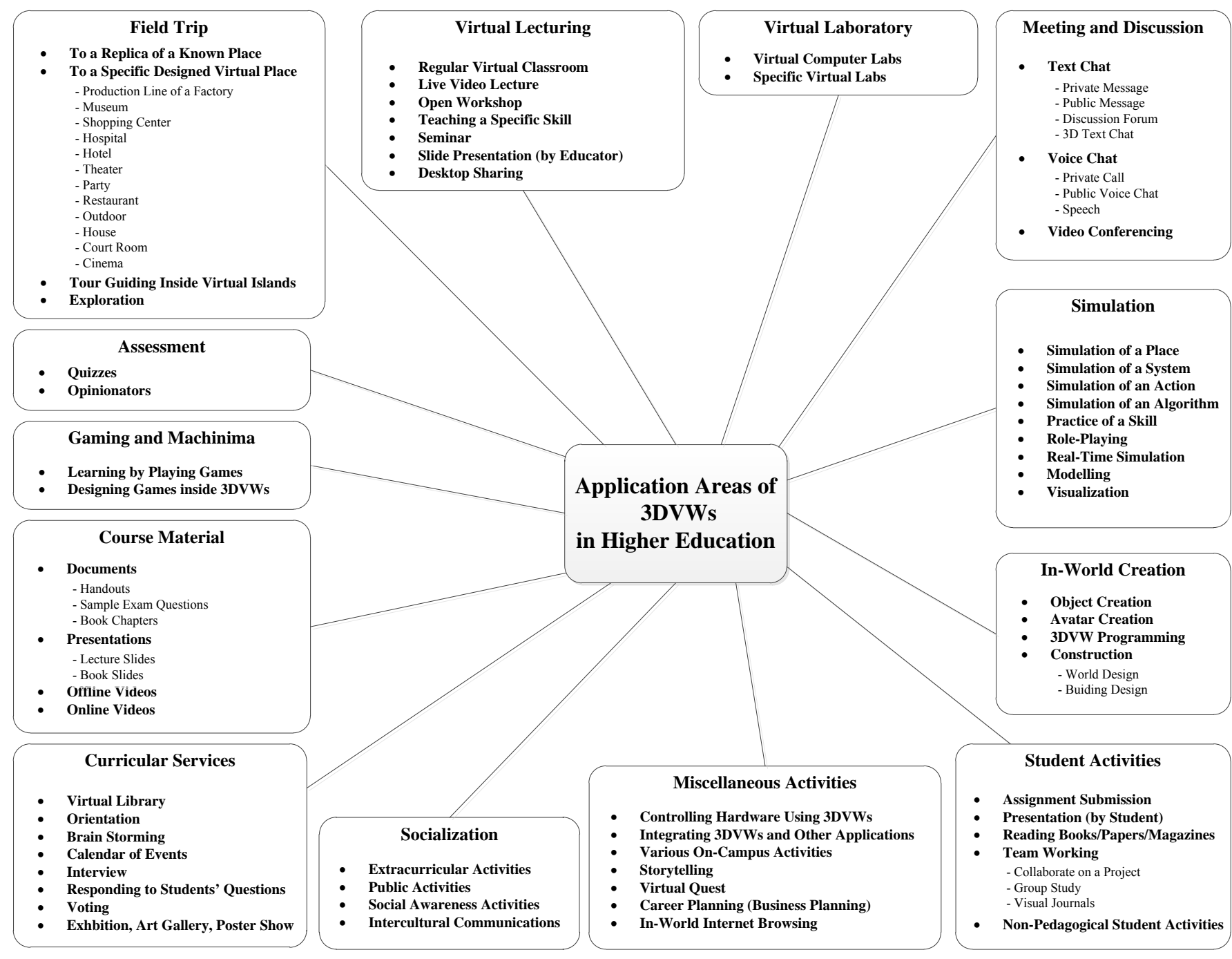

Figure 6. A taxonomy of application areas of 3DVWs in higher education. 
Virtual lecturing. Total of 73 studies in this category, applied a virtual replica of a classroom setting or lecture theatre as commonly used for accommodating classes and conducting sessions, presentations, lectures and seminars. The instructors could use virtual screens to present slides, videos, pictures, web resources, and an online desktop when a part of the desktop needs to be presented. Activities in this category were divided into seven subcategories such as regular virtual classroom, live video lecture, open workshop, and so on. Students usually attend the virtual classroom using their own avatars, and there are possibilities to communication to the instructor and other students using text or voice chat.

Virtual laboratory. This category included 14 studies that designed and implemented virtual laboratories in virtual worlds for educational purposes. Virtual labs are equipped with virtual replicas of real laboratory equipment that users can access remotely by using the Internet. Virtual laboratories are available 24 hours a day and can provide access to the most remote resources. In comparison with real-world laboratories, they are inexpensive, more complex, and sophisticated. Virtual laboratories category was divided into two subcategories: virtual computer labs and specific virtual labs.

Field trip. This category was based mainly on self-learning. A virtual representation of a specific place such as a museum, a gallery, a hotel, a hospital or a scientific site is designed to create visitor awareness about the place and provide information that students need to learn. Users can travel to the designed space, walk or fly around the various parts of the place, read the provided information and see some activities inside the location. This kind of activity is a great opportunity for learners to gain awareness about a historical place and find out information about popular places which are inaccessible or too expensive to travel to in the real world. According to the findings, virtual field trips include four types of activities: a trip to a replica of a known place in the real world, a trip to a specific designed place such as a hotel, museum, factory, restaurant, etc.; a tour of a virtual island, and an exploration. Overall, 24 studies had field trip activities using 3DVWs.

Meeting and discussion. Discussion boards and online meetings are other activities in the 3DVW-related virtual learning programs in the literature. This category refers to the application of 3DVWs to communicate from one avatar to others or from one person to another. Participants from geographically disperse places can attend the virtual venue and interact with each other using verbal or non-verbal communication. Verbal communication is established synchronously with voice, live video and text-based chat functions, and nonverbal communication is established through avatars' appearance, postures and gestures. During online group discussions or remote virtual meetings, students participate in social and interactive activities such as collaborative discussions, interviews, asking questions about a subject or course, consultations, and so on. In sum, 55 studies had content related to this category.

Simulation. A total of 42 studies in the literature applied 3DVWs for simulations. One of the fundamental attributes of this technology is its capability to provide a simulation of $3 \mathrm{D}$ spaces or spatial aspects. Simulation is used for teaching and learning processes that generally are impossible or very hard to practice in the real world. By using simulation techniques, the virtual clones of a specific place, environment or activity are modelled and designed for training purposes. Working with simulated environments familiarize students with intended concepts and learning environments which are usually inaccessible in the real world. Simulation contributes to their learning through acting, observing the outcomes of 
their actions, examining their own hypotheses regarding various concepts and reflecting on their own understanding. The simulation category in our classification is divided into different sub-categories such as practice of a skill, role-playing, simulation of an action, simulation of a system, and so on.

In-world creation. 17 studies in this category contain activities related to designing, building and creating objects in virtual space. Students are able to develop virtual objects using a combination of software and a programming language. Most 3DVW platforms provide a specific programming language and building tool to facilitate the creation and design of objects in the virtual world. For instance, Second Life provided Linden Scripting Language (LSL), a scripting programming language, as well as a building software for programmers to design inside the virtual world. Students involve in construction and creation of objects and avatars within the virtual environment.

Gaming and machinima. In recent years, the advent of 3DVWs has presented new opportunities for developing game-based learning. There is an intense relation between 3D virtual environments and computer games. As 3DVWs provide a wide range of online activities, they have the capability to support massive multiplayer online gaming platforms. Although these 3DVWs can be used as a computer game, they do not have most of the main characteristics of traditional computer games such as winner, loser, scores and levels. They are also known as serious games. While playing the game, students tend to learn various educational concepts. 17 studies in the literature used games as a powerful tool for education. Gaming activities were divided into two sub-categories: learning by playing games and designing games inside virtual worlds.

Assessment. A group of nine studies used 3DVWs as a tool for evaluation and assessment purposes in education. Mostly, they held quizzes or activities for assessment of students' understanding of a course or a skill inside the virtual worlds. Two kinds of activities were carried out for assessment purposes: quizzes and opinionators (places in the virtual environment with questions and answers such as agree and disagree).

Course material. Another activity aimed at facilitating students' access to courserelated resources. In 16 studies in the literature, a place was developed to provide all of the required course material such as documents, presentations, and offline and online videos (such as YouTube videos). With virtual screens designed, programmed and connected to the online video websites, the video is displayed directly from the website by clicking a display. Students also can click on various objects inside the world to view, read and download resources in different formats such as image, PDF, Word, Excel and PowerPoint.

Student activities. This category is relevant to different activities carried out by students such as assignment submission, presentation, team and group work (e.g. collaboration on projects or group studies), and reading books and magazines provided in the virtual worlds. The environments designed in these studies mainly provided the ability for students to perform educational exercises without supervision from educators. There were some non-pedagogical student activities such as art works, activities to experience and learn English, and cultural introductions presenting photos related to students' own traditions, hometown and country. A total of 35 studies had contents related to this category.

Socialization. That a 3DVW plays a crucial role in social interaction of users is an undeniable fact. This technology is a part of a major group of Internet-based applications 
known as social media. According to Kaplan and Haenlein (2009), within social media, 3DVWs have three main characteristics that distinguish them from technologies. First, they authorize their users to interact with other users in real time. Second, they enable users to create a fully customized virtual avatar. Finally, these worlds provide the ability of exploring 3D virtual environments. Due to a sophisticated communicating facilities provided by these technologies, they make interactions very pleasant and delightful. Seven studies used this technology to involve students in socialization activities. By using these worlds, students are persuaded to participate in activities such as social awareness activities, intercultural communications, and public and extracurricular activities.

Curricular services. A group of 27 studies were categorised in curricular services which include activities such as virtual library services, orientation programs, brainstorming scenarios, interviews, exhibitions, art galleries and other curricular-related activities.

Miscellaneous activities. There were some educational activities using 3DVWs that were not related to the aforementioned categories. Therefore, we classified them as miscellaneous activities. The significant activities in this category were controlling hardware using 3DVWs, integrating 3DVWs with other applications, storytelling, virtual quests and so on. A total of 24 studies fit into this category.

\section{Participant Population}

Depending on different target users of the virtual learning environments, three categories were created: learner participants, instructor participants and facilitator participants. In the learner participants group, there are five user categories: university students, educators, faculty members, managers and executives.

In the instructor group, there are lecturers, teachers, tutors and faculty members performing as trainers or educators. The third group of participants includes other roles in the activities as a facilitator, such as virtual patients, customers, librarians and university staff. Figure 7 presents the population groups participated in 3DVW-related activities in higher education.
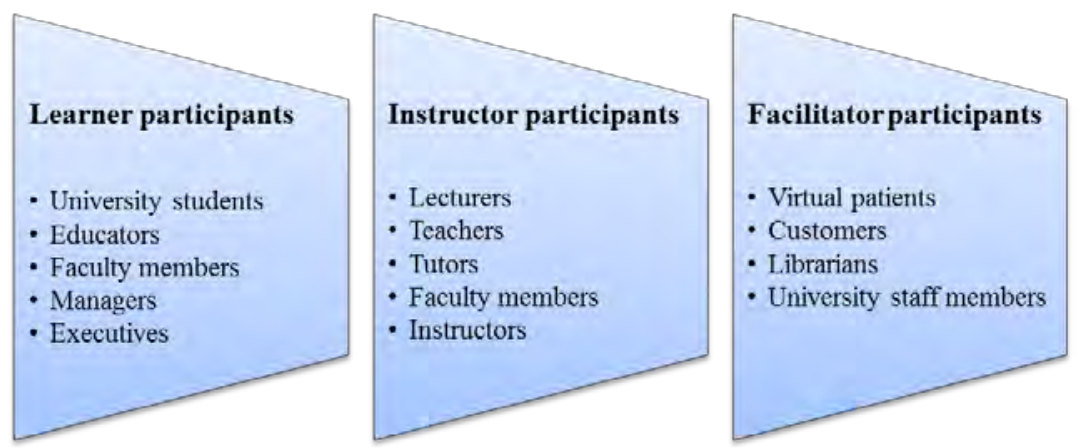

Figure 7. Population groups that used 3DVWs in virtual educational activities in higher education.

\section{Discussion}

After analysing the findings, some critical points relevant to application of 3DVWs in higher education were extracted.

Despite the fact that some of the studies were carried out using qualitative, quantitative and mixed methods for their data collections, and clearly reported their results, the majority of the studies did not report their methods of data collection, data analysis, theories used, number of participants or the results of their findings. Therefore, it was difficult to achieve precise theoretical findings based on the studies. 
The majority of the studies reported a very successful and innovative form of virtual classroom experience in comparison with a real-world classroom. Similarly, a large number of studies that used virtual laboratories obtained very promising results. Studies in the area of virtual field trips found that although there are some technological limitations such as low graphics performance and visual effects, as well as students' perception of relevance, virtual field trips are more innovative. In terms of meetings and discussions, the previous research found very successful results. A wide range of studies reported that 3DVW is a very successful and outstanding tool for holding meetings, online forums and discussion boards, and 3DVW-based team work can improve both student and instructor interaction patterns and the strength of the group's relationship.

Many studies that used 3DVWs for simulation, reported that this technology can play a crucial role in education and provide a practical tool for students to examine their skills. Similarly, the majority of studies that used 3DVWs for in-world creations, found that these platforms provide a higher level of flexibility for the creation of various environments and objects, implementation of algorithms, design of games, and assigning of a variety of actions to objects. In gaming and machinima, a large portion of research found 3DVW to be an appropriate tool for designing games and implementing game-based learning.

From the studies using the technology for student assessment, not enough positive results have been reported. Due to the three-dimensional characteristic of virtual worlds and the need for a higher level of processing, this technology seems to be unsuitable for assessment, and more development is required.

Most studies in the category of course materials found this application feasible and useful. According to their findings, presenting resources for students in a virtual environment was very successful.

Most studies in the category of socialization found it to be a very successful experience for enhancing social abilities among higher education students. Despite the advantages of 3DVWs for students' social interaction, applying this technology sometimes can distract undergraduate students from their academic studies.

Studies in the categories of student activities, curricular services and miscellaneous activities found the technology very useful and promising for the future. The results showed that the technology has the potential to be utilized as a basic platform to perform various pedagogical and educational activities and services.

The most reported issues which could affect the efficiency of 3DVWs in higher education were lower hardware performance, limited Internet speed and technical problems. Furthermore, in most experiences, there was no possibility to limit students' behaviours within the virtual classroom as well as the appearance of their avatar. Lack of a personal computer or smart device as well as limited access to the Internet also could be a significant problem for a student.

By taking all above arguments into consideration, it can be concluded that the advantages of using 3DVWs in higher education far outweigh the disadvantages. There were unsuccessful experiences, however, in some education-related activities in the literature as well; therefore, new developments still are required. The major issues regarding the use of 3DVWs in the higher education sector are that these platforms:

i. are in the early stages of development and have barriers and challenges to overcome

ii. have technical bugs that must be rectified

iii. require high-speed Internet access

iv. require high-performance hardware to process graphics

v. require more realistic graphics

vi. require data security measures 
vii. require user activity control

Figure 8 illustrates the frequency of studies included in each categories of activities. As can be seen, many studies contained more than one activity in their experience and were included in more than one category.

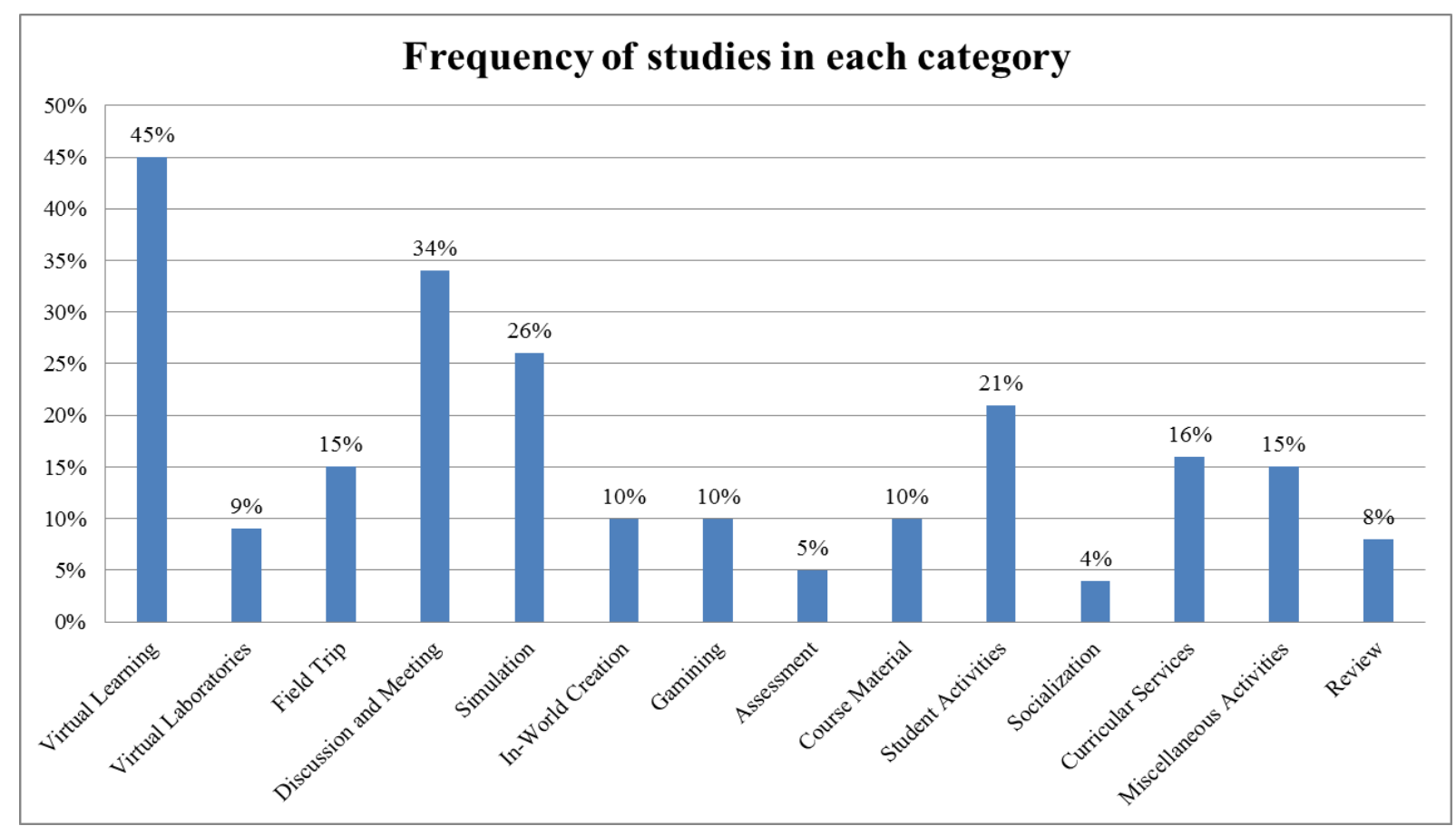

Figure 8. Frequency of studies included in each category of activities.

\section{Implications for Research}

Although researchers paid more attention to the educational applications of 3DVWs, there are some gaps in the literature and future research is required to explore improvements to the previous studies.

Most studies in the literature had limited and short-term educational programs on 3DVWs, and they normally were sections of a courses or maximum one semester courses. Future studies should extend the duration of their educational program to more than one semester or even more than 1 year. Performing longitudinal studies provides opportunities for researchers to examine the effects of applying these technologies over a long period of time to demonstrate the novelty effects of technology, which has not been investigated at all heretofore.

Future research is expected to deeply examine various social as well as cultural factors that impact the application of these technologies among higher education students, especially by investigating various methods of application of these technologies within various cultural contexts.

As these technologies provide great opportunities for students with respect to collaborative learning, team work and self-learning, future studies may best contribute by investigating the impact of utilizing these technologies on individual and group outcomes by applying various teaching and learning methods and theories.

Existing studies also pay little attention to the gaming and machinima aspect of 3DVWs in education. Researchers should increasingly recognize the impact of entertaining environments and leisure activities, and utilize computer, video games, and especially 3DVWs as remarkable educational resources. There also is a need for further research investigating the issues and barriers of using 3DVWs in higher education. 
A majority of the research in this field has been conducted in North America and Europe, and there are a limited number of research studies available from other countries. We recommend comparative research within various cultural and social environments to more effectively comprehend the influence of geographical contexts on utilizing 3DVWs in the higher education sector.

\section{Implications for Practice}

In spite of the fact that a considerable amount of research is relevant to utilization of 3DVWs in higher education across the world, practical applications are seemingly inadequate as several opportunities have arisen for using this technology in the field of higher education.

Due to the Internet-based characteristics of 3DVWs, they provide great opportunities for distance learning and e-learning programs. Lectures, seminars, laboratories and workshops can be held easily using this technology, and students and educators can attend the virtual venue by using their own avatar from various locations across the world.

According to the excellent potential of 3DVWs for modelling and simulation purposes, studies or practices which are not practical or feasible in the real-world environments could be performed using simulations within 3D virtual environments.

By constructing boardrooms, auditoriums and meeting rooms where virtual materials can be created, stored and presented, a variety of pedagogical communities such as universities, colleges and private groups - as well as businesses, organizations and corporations - have the opportunity to use this technology to hold workshops and provide access to discussion boards, seminars, presentations, meetings and other similar activities.

Based on the great potential that 3DVWs have for librarians, instructors and educators in remote locations, organizations could establish virtual libraries to provide remote access to uploaded electronic books, magazines, newspapers, videos and other types of documents.

3DVWs provide opportunities for collaboration and networking on a global scale. Like social media and other Web 2.0 applications, this technology can play a significant role in improving interaction and socialization among educators and students.

\section{Conclusion}

As a conclusion, the objective of the current literature review was to find and investigate previous studies applying 3DVW technology for pedagogical purposes in higher education. To find relevant studies, an extensive search of eight digital libraries was performed. Out of 1,402 studies found in digital libraries, 165 studies which were published in peer-reviewed journals and conference proceedings from 1 January 1990 until 15 November 2013 were included and evaluated in this review. A range of applications of 3DVWs for educational purposes in each study were extracted. To achieve new insights, all applications were fit into meaningful categories. This systematic literature review provides implications for future research as well as several practical implications for researchers who are attentive in exploring pedagogical opportunities using 3DVW technology.

\section{Disclosure of Potential Conflicts of Interest}

The authors declare that they have no conflict of interest.

\section{Acknowledgment}

We would like to acknowledge that some of the preliminary findings of the current research have been published as a book chapter in www.igi-global.com (Ghanbarzadeh \& Ghapanchi, 2016). This current paper, however, is extensively expanded from the book 
chapter. We greatly appreciate the editors' and reviewer's efforts to carefully review the paper and for their valuable suggestions.

\section{References}

Ba, S., Ke, D., Stallaert, J., \& Zhang, Z. (2010). Why give away something for nothing? Investigating virtual goods pricing and permission strategies. ACM Transactions on Management Information Systems (TMIS), 1(1), 4.

Blair, J., \& Lin, F. (2011). An approach for integrating 3D virtual worlds with multiagent systems. Paper presented at the Advanced Information Networking and Applications (WAINA), 2011 IEEE Workshops of International Conference on.

Boulos, M. N. K., Hetherington, L., \& Wheeler, S. (2007). Second Life: an overview of the potential of 3-D virtual worlds in medical and health education. Health Information \& Libraries Journal, 24(4), 233245.

Damer, B. (2008). Meeting in the ether: A brief history of virtual worlds as a medium for user-created events. Artifact, 2(2), 94-107.

De Lucia, A., Francese, R., Passero, I., \& Tortora, G. (2009). Development and evaluation of a system enhancing Second Life to support synchronous role-based collaborative learning. Software: Practice and Experience, 39(12), 1025-1054.

Duncan, I., Miller, A., \& Jiang, S. (2012). A taxonomy of virtual worlds usage in education. British Journal of Educational Technology, 43(6), 949-964.

Firat, M. (2010). Learning in 3D virtual worlds and current situation in Turkey. Procedia-Social and Behavioral Sciences, 9, 249-254.

Ghanbarzadeh, R., \& Ghapanchi, A. H. (2016). Applied Areas of Three Dimensional Virtual Worlds in Learning and Teaching: A Review of Higher Education. Emerging Tools and Applications of Virtual Reality in Education, 26.

Gorini, A., Gaggioli, A., Vigna, C., \& Riva, G. (2008). A second life for eHealth: prospects for the use of 3-D virtual worlds in clinical psychology. Journal of Medical Internet Research, 10(3).

Kaplan, A. M., \& Haenlein, M. (2009). The fairyland of Second Life: Virtual social worlds and how to use them. Business horizons, 52(6), 563-572.

Kitchenham, B. (2004). Procedures for performing systematic reviews. Keele, UK, Keele University, 33, 2004.

Linden Lab. (2013, 20/06/2013). SL10B Infographic: Ten Years of Second Life. Retrieved from http://www.lindenlab.com/releases/infographic-10-years-of-second-life

Merchant, Z., Goetz, E. T., Cifuentes, L., Keeney-Kennicutt, W., \& Davis, T. J. (2014). Effectiveness of virtual reality-based instruction on students' learning outcomes in K-12 and higher education: A meta-analysis. Computers \& Education, 70, 29-40.

The bibliography for all the analysed papers is available at $<$ Link $>$

\section{Appendices}

Appendix A and Appendix B are available at $<$ Link $>$ 